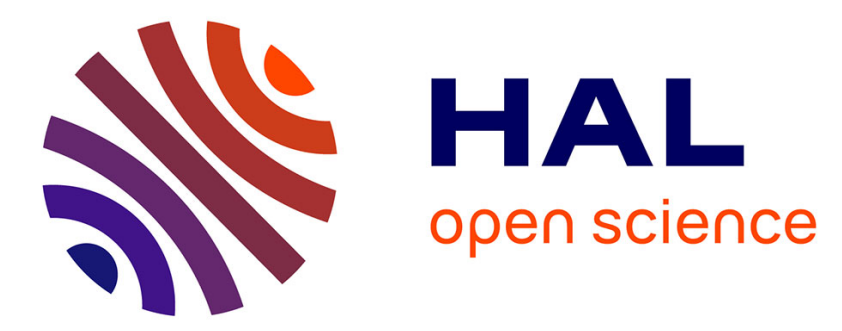

\title{
The Role of Internet of Services (IoS) on Industry 4.0 Through the Service Oriented Architecture (SOA)
}

\author{
Jacqueline Zonichenn Reis, Rodrigo Franco Gonçalves
}

\section{To cite this version:}

Jacqueline Zonichenn Reis, Rodrigo Franco Gonçalves. The Role of Internet of Services (IoS) on Industry 4.0 Through the Service Oriented Architecture (SOA). IFIP International Conference on Advances in Production Management Systems (APMS), Aug 2018, Seoul, South Korea. pp.20-26, 10.1007/978-3-319-99707-0_3 . hal-02177890

\section{HAL Id: hal-02177890 \\ https://hal.inria.fr/hal-02177890}

Submitted on 9 Jul 2019

HAL is a multi-disciplinary open access archive for the deposit and dissemination of scientific research documents, whether they are published or not. The documents may come from teaching and research institutions in France or abroad, or from public or private research centers.
L'archive ouverte pluridisciplinaire HAL, est destinée au dépôt et à la diffusion de documents scientifiques de niveau recherche, publiés ou non, émanant des établissements d'enseignement et de recherche français ou étrangers, des laboratoires publics ou privés. 


\title{
The role of Internet of Services (IoS) on Industry 4.0 through the Service Oriented Architecture (SOA)
}

\author{
Jacqueline Zonichenn Reis ${ }^{1}$ and Rodrigo Franco Gonçalves ${ }^{1}$ \\ ${ }^{1}$ Paulista University, São Paulo, Brazil \\ \{zonichenn@hotmail.com, rofranco212@gmail.com\}
}

\begin{abstract}
Many different concepts and approaches have been seen for an Industry 4.0 achievement. In the attempt of merging the theory to the practice, there are gaps to determine which concept or technology suits best the productive chain and what is really a pre-requisite to classify it as Industry 4.0. On scientific and empirical literature about this subject, the Internet of Services, IoS, has been mentioned as an important pillar for Industry 4.0, coupled with Internet of Things (IoT) and Cyber-physical systems (CPS). While IoT and CPS as well as their link with Industry 4.0 are detailed in many researches, a deeper understanding on the Internet of Services and its contribution for this scenario is still missing. This paper aims to fill this gap gathering concepts about the Internet of Services, how it is composed and what would be its role on the manufacturing environment. Through a deeper understanding about the origin of the term Internet of Services, there is an important concept that may explain how the Industry 4.0 operates in a business and technological perspective: the concept of SOA - Service Oriented Architecture.
\end{abstract}

Keywords: Internet of Services, Industry 4.0, Service-Oriented Architecture

\section{Introduction}

After some years that Industry 4.0 was first coined, companies are still looking for the best approach and trying to understand this new paradigm. The manufacturers' dilemma is whether they should commit into Industry 4.0 and which technology would be the most suitable to adopt, considering the investment required and the benefits on productivity [1].

Historically, the first three industrial revolutions came as a result of mechanization, electricity and Information Technology respectively. Now, the introduction of the Internet of Things and the Internet of Services into the manufacturing environment leads to a fourth industrial revolution [2]

Although the Internet of Services is considered by many authors as one of the main pillars of Industry 4.0 [2-5], there is still a gap on the literature in addressing the full meaning of Internet of Services and its contribution on this new environment.

Comparing Internet of Services against the Internet of Things on literature about Industry 4.0, the number of papers reflect a more expressive focus on IoT while IoS is still not so explored. 
Moreover, Internet of Services brings itself a more intangible perspective which is natural from services [6]. While IoT deals with tangible objects, sensors and machines, the Internet of Services will cover a more abstract set of functionalities, bringing the concept of SOA, Service-Oriented Architecture.

Service-Oriented Architecture SOA is a logical model that reorganize software applications and infrastructure into a set of interacting services [7]. By exploring the concept of SOA, it is expected that the meaning of Internet of Services and Industry 4.0 becomes more clear, reinforcing the relevance of this study.

The aim of this research is characterize the Internet of Services explaining its composition and its role on Industry 4.0.

This paper is organized as follows: After this introduction, the second section brings the research method. The third section gives a contextualization on Industry 4.0. The forth section covers the foundation of Internet of Services and reveals the concept of Service Oriented Architecture. The fifth section links such concepts to the manufacturing environment, followed by a conclusion.

\section{Research Method}

This paper is a theoretical development based in bibliographic, but not systematic, review about Industry 4.0 and Internet of Services concepts, looking for the role of IoS in this new manufacturing environment.

An initial search was conducted using two comparative strings in the bases Google Scholar, Science Direct and Web of Science, looking for the relevance and originality of the subject.

Table 1: Boolean Strings used for the research

\begin{tabular}{l|c|c|c}
\hline \multirow{2}{*}{ String } & \multicolumn{3}{|c}{ Finds } \\
\cline { 2 - 4 } & Google Scholar & Science Direct & $\begin{array}{c}\text { Web of } \\
\text { Science }\end{array}$ \\
\hline "Internet of Things" AND "Industry 4.0" & 7660 & 492 & 252 \\
\hline "Internet of Services" AND "Industry 4.0" & 579 & 61 & 9 \\
\hline
\end{tabular}

As shown in Table 1, there are much less results when placing Internet of Services on the string.

Given the small number of resulting papers, the study becomes exploratory, without a specific inclusion or exclusion criteria for papers selection.

After gathering concepts that link the subjects Internet of Services and Industry 4.0, the study was refined into such correlations and a new model approach has beenproposed for a smart manufacturing environment. 


\section{$3 \quad$ Industry 4.0}

The term Industry 4.0, was rooted in the German federal government's strategy in 2011 [2]. This German Government's initiative had the aim of gaining stronghold in global manufacturing by advanced application of information and communication systems. Through the application of new technologies in manufacturing, the entire factory environment becomes smart and enables mass customization [3].

Industry 4.0 is defined as a collective term for technologies and concepts of value chain organization [4]. Among this set of technologies, the protagonist ones would be Cyber Physical Systems, Internet of Things and Internet of Services [2-5]. Cyber Physical Systems (CPS) are sensors and actuators that monitor physical processes and create a virtual copy of the physical world. Over the Internet of Things, CPS communicate and co-operate with each other and humans in real time. Then through the Internet of Services (IoS), both internal and cross organizational services are offered and utilized by participants of the value chain [4].

The own promoters of the German program explain that Industry 4.0 involves the technical integration of IoT and IoS as enablers to create networks, incorporating the entire manufacturing process that convert factories into a smart environment [2].

As seen on Research Method section, while most papers in scientific literature cover Internet of Things, this paper focus on Internet of Services or IoS, addressing the service context and going beyond the infrastructure and connectivity domains.

\section{$4 \quad$ Internet of Services}

The term Internet of Services raised from the convergence of other two concepts: Web 2.0 and SOA - Service-oriented architecture [8]. The intersection of these two fields is the notion of reusing and composing existing resources and services.

The first concept, Web 2.0 is characterized by four aspects: interactivity, social networks, tagging and web services [9].

- Interactivity: this gain comes from two technologies: AJAX (Asynchronous JavaScript and XML) that allows the communication and the dynamic manipulation of data between a server and the Web browser;

- Social networks: the social networks up come based on common interests and make the information from each network available through different ways;

- Tagging: users can add a key-word as a tag to a certain Web content, making this tag easily reachable when searched by other users;

- Web Services: allow that other software make use of the features offered by a Web application, being available not only to people but also to machines.

The second concept that forms the Internet of Services is the Service Oriented Architecture - SOA [8]. SOA is a way of designing and building a set of Information Technology applications where application components and Web Services make their functions available on the same access channel for mutual use. In order to satisfy these requirements services should be [7]: 
- Technology neutral: they must be invoked through standardized lowest common denominator technologies that are available to almost all IT environments. This implies that the invocation mechanisms (protocols, descriptions and discovery mechanisms) should comply with widely accepted standards.

- Loosely coupled: they must not require knowledge or any internal structures or conventions (context) at the client or service side.

- Support location transparency: services should have their definitions and location information stored in a repository such as UDDI and be accessible by a variety of clients that can invoke the services irrespective of their location.

\subsection{Service Oriented Architecture - SOA}

The Service Oriented Architecture - SOA - can be explained through two different angles. From a business perspective, it represents a set of services that improve the capability of the company to conduct business with customers and suppliers. From a technology perspective, it is a project philosophy characterized by modularity, separation of concerns, service re-uses, and composition, as well as a new programming method based [10].

Web Services technology constitutes the main vehicle for service-oriented architectures. Web Service is defined as "a software system designed to support interoperable machine-to-machine interaction over a network". It has an interface described in a machine-process format that informs what the service does and how to call its functions. Basically, Web Services on-line delivery functionalities (called services) offer simple input and output interfaces - hiding its internal structure and programming language - that can be used by other Web Service, software application or machine, as well as humans [11].

Through the concept of Service-Oriented Architecture, new applications can be assembled from the available components and services, like a LEGO®. In SOA, all applications in an organization can offer and consume services in a unique and integrated communication channel, called Enterprise Service Bus, as a simple way to facilitate integration [12].

\section{$5 \quad$ Application of Service-Oriented Architecture on Industry 4.0}

In the computer science domain, the service-oriented paradigm defines the principles for conceiving decentralized control architectures that decompose computational processes into sub-processes, called services. The focus of SOA is to leverage the creation of reusable and interoperable function blocks in order to reduce the amount of reprogramming efforts [13].

As a metaphor, it is like a shopping mall underground floor in which various services such as barber shop, cell phones repair, tailor's shop are offered in a same physical location, facilitating customer access.

In a cloud manufacturing system, various manufacturing resources and abilities can be intelligently sensed and connected into the wider Internet by means of SOA principles. As a result, the Service Oriented Manufacturing Systems (SOMS) emerges. A 
promising approach to develop SOMS is the integration of multi-agent system (MAS) with Service Oriented Architectures (SOA) [14].

Within the Industry 4.0 it works as a service bus, as placed in Fig 1, where different robots, machines and applications are available for the manufacturing process. The different services can be accessed, matched and integrated by discovery and composition applications creating a Service-Oriented Manufacturing Architecture (SOMA) which is an approach we developed for an Industry 4.0 smart manufacturing environment.

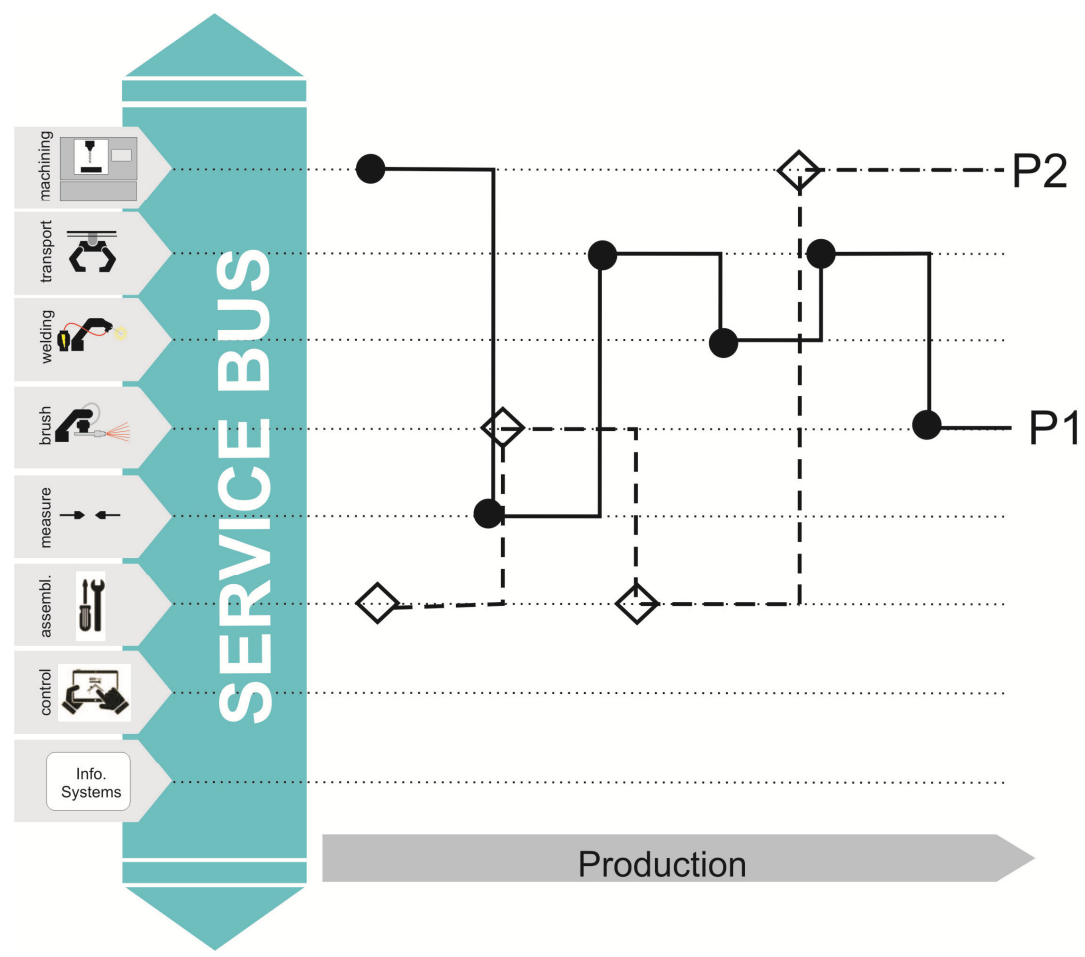

Fig. 1. Service-Oriented Manufacturing Architecture (SOMA). Source: the authors

On Figure 1, instead of a traditional product-oriented environment, there is a service-oriented manufacturing. Both Process and Products (P1, P2) invoke the necessary services, which are shared through the Service Bus following a flexible and modular smart productive chain.

While making decisions by using its own sensors and actuators, the product itself can trace the better configurable line along the factory.

Also, by using this architecture, enterprises can generate their own manufacturing services for the participation on an external supply chain, in addition to the management of the internal supply chain. This generates the Internet of Services [15].

A similar approach called Intelligent Enterprise Service-based Bus (iESB) [16] have been proposed to interconnect several factories systems to each other. The archi- 
tecture is based on Intelligent Services defined as independent pieces of software that are expected to provide a particular result, either produced by the Intelligent Service itself or by requesting support from other Intelligent Services. Our approach instead is exploring the interaction from the product or process within the factory, making use of the Industry 4.0 components that would be the Cyber Physical Systems or smart products.

Another similar SOA product-based models have been proposed [17], but not using the Service Bus. Moreover, they are prior to the Industry 4.0 model conception.

Our framework is based on the pillars of the Industry 4.0 such as Cyber Physical Systems, Internet of Things and Internet of Services. Moreover, we confirm from the study, that the Internet of Services is one of the main enablers to create networks and convert factories into a smart environment, what is achieved through the ServiceOriented Architecture.

\section{Conclusion}

This paper links the concepts of Industry 4.0, Internet of Services and ServiceOriented Architecture giving more emphasis to the service domain of manufacturing environment.

A service bus is illustrated to explain the idea of a Service-Oriented Manufacturing Architecture (SOMA), based on SOA, which is explained to better characterize the Internet of Services as one of the pillars of the Industry 4.0.

All manufacturing elements, like automated machine-tools, robots, human workers and information systems, have their functions available in the abstract form of services, exchanging data and instructions through the Service Bus.

\section{References}

1. Sanders, A, Elangeswaran, C., Wulfsberg, J.: Industry 4.0 implies lean manufacturing: Research activities in industry 4.0 function as enablers for lean manufacturing, Journal of Industrial Engineering and Management, v. 9, n. 3, p. 811 (2016)

2. Kagermann, H., Wahlster, H., Helbig, J.: Securing the future of German manufacturing industry: Recommendations for implementing the strategic initiative INDUSTRIE 4.0 - Final Report of the Industrie 4.0 working group. Acatech - National Academy of Science and Engineering, pp. 1-82 (2013)

3. Satyro, W, Sacomano, J. B., Silva, M. T., Gonçalves, R. F., Contador, J. C., Cieminski, G.: Industry 4.0: Evolution of the Research at the APMS Conference, in: LÖDDING, Hermann et al (Orgs.), Advances in Production Management Systems. The Path to Intelligent, Collaborative and Sustainable Manufacturing, Cham: Springer International Publishing, v. 513 , p. 39-47 (2017)

4. Hermann, M., Pentek, T., Otto, B.: Design principles for industrie 4.0 scenarios: a literature review. In: Working Paper No. 01/ 2015, Technische Universität Dortmund, Fakultät Maschinenbau and Audi Stiftungslehrstuhl - Supply Net, Order Management (2015)

5. Hofmann, E.; Rusch, M.. Industry 4.0 and the current status as well as future prospects on logistics. Computers in Industry, v. 89, p. 23-34 (2017) 
6. Cardoso, J., Voigt, K., Winkler, M.: Service Engineering for the Internet of Services. In: Enterprise Information Systems. [s.1.]: Springer, Berlin, Heidelberg, p. 15-27 (2008)

7. Papazoglou, Mike P.: Service-Oriented Computing: Concepts, Characteristics and Directions, in: International Conference on Web Information Systems Engineering et al (Orgs.), Proceedings/Fourth International Conference on Web Information Systems Engineering, WISE 2003: IEEE Computer Society (2003)

8. Schroth, C.; Janner, T.: Web 2.0 and SOA: Converging Concepts Enabling the Internet of Services. IT Professional, v. 9, n. 3, p. 36-41 (2007)

9. Treese, W.: Web 2.0: is it really different? NetWorker, v. 10, n. 2, pp. 15-17 (2006).

10. Ordanini, A., Pasini, P.: Service co-production and value co-creation: The case for a service-oriented architecture, European Management Journal, v. 26, n. 5, p. $289-297$ (2008)

11. W3C - World Wide Web Consortium. Web Services Architecture, https://www.w3.org/TR/ws-arch/

12. Robin Singh Bhadoria, Narendra S. Chaudhari, V.G. Tharinda Nishantha Vidanagama, Analyzing the role of interfaces in enterprise service bus: A middleware epitome for service-oriented systems. Computer Standards \& Interfaces, Vol. 55, pp. 146-155 (2018)

13. Gamboa, F. Q.; Cardin, O.; L’Anton A.; Castagna, P.: A modeling framework for manufacturing services in Service-oriented Holonic Manufacturing Systems. Engineering Applications of Artificial Intelligence, v. 55, p. 26-36 (2016)

14. Giret, A.; Garcia, E.; Botti, V.: An engineering framework for Service-Oriented Intelligent Manufacturing Systems. Computers in Industry, v. 81, p. 116-127 (2016)

15. Tao, F.; Cheng Y.; Xu L.; Zhang, L,; Li B.: CCIoT-CMfg: Cloud Computing and Internet of Things-Based Cloud Manufacturing Service System, IEEE Transactions on Industrial Informatics, v. 10, n. 2, p. 1435-1442 (2014).

16. Marin, C.A.; Monch, L.; Leitao, P.; Vrba, P.; Kazanskaia, D.; Chepegin, V.; Liu, L.; Mehandjiev, N.: A Conceptual Architecture Based on Intelligent Services for Manufacturing Support Systems. IEEE, p. 4749-4754 (2013).

17. Nagorny, K.; Colombo, A.; Schmidtmann, U.: A service- and multi-agent-oriented manufacturing automation architecture. Computers in Industry 63, p. 813-823 (2012). 